九州大学学術情報リポジトリ

Kyushu University Institutional Repository

\title{
Synthesis and Insect Growth Regulatory Activity of 1-Neopentyl-5-substituted Imidazoles
}

\section{Kuwano, Ei ichi}

Laboratory of Pesticide Chemistry, Faculty of Agriculture, Kyushu University

Kikuchi, Masamichi

Laboratory of Pesticide Chemistry, Faculty of Agriculture, Kyushu University

Eto, Morifusa

Laboratory of Pesticide Chemistry, Faculty of Agriculture, Kyushu University

https://doi.org/10.5109/23947

出版情報 : 九州大学大学院農学研究院紀要. 35 (1/2)，pp. 35-41，1990-12. Kyushu University バージョン：

権利関係 : 


\title{
Synthesis and Insect Growth Regulatory Activity of 1-Neopentyl-5-substituted Imidazoles
}

\author{
Eiichi Kuwano, Masamichi Kikuchi and Morifusa Eto \\ Laboratory of Pesticide Chemistry, Faculty of Agriculture, \\ Kyushu university 46-02, Fukuoka 812
}

(Received June 19, 1990)

\begin{abstract}
A new series of 1-neopentyl-5-substituted imidazoles was synthesized and evaluated in silkworms, Bombyx mori, for activity inducing precocious metamorphosis. Most of the compounds induced precocious methamorphosis in the 4 th instar larvae of $B$. mori by topical application (20 $\mathrm{g}$ /larva). 1-Neopentyl-5-phenylimidazole (1) showed relatively high activity. The introduction of a methoxy (KK-109) or an ethoxy (KK-110) substituent at the ortho position on the benzene ring increased the activity compared with that of compound 1, while the 4-alkoxyphenyl analogs showed decreased activity. The 4-chlorophenyl (KK-135) and 4-bromophenyl analogs also exhibited high activity. When the 3rd instar larvae were treated with a high dose of KK-110 or KK-135, a few larvae metamorphosed into precocious miniature pupae in the 3rd larval stage. The induction of precocious metamorphosis with KK-110 and $\mathrm{KK}-135$ was inhibited by simultaneous application of methoprene, a juvenile hormone mimic.
\end{abstract}

\section{INTRODUCTION}

Recently we have reported that a large number of 1, 5-disubstituted imidazoles with a juvenile hormone ( $\mathrm{JH}$ )-like terpene chain induced unequivocal precocious metamorphosis in silkworm, Bombyx mori, larvae, which was clearly recognized as a JH-deficiency symptom. 1-Citronellyl-5-phenylimidazole (KK-22) (Kuwano et al., 1984) and 1-benzyl-5-[(E)-2,6-dimethyl-1, 7-heptadienyl] imidazole (KK-42) (Kuwano et al., 1985) have been found as two representative compounds showing marked activity. However, further investigations demonstrated that the JH-like terpene chain was not necessary for the activity; 1-neopentyl-5-phenylimidazole showed an activity comparable to KK-22. In our previous short communication (Kuwano et al., 1988), we reported on the activity of several 1, 5-disubstituted imidazoles with a non-terpene chain. In this paper we describe details of the preparation and structure-activity relationships of 1-neopentyl-5-substituted imidazoles.

\section{EXPERIMENTAL}

Synthesis

All melting points were uncorrected. The NMR spectra were determined with a JEOL JNM-FX 100 spectrometer, using $\mathrm{Me}_{4} \mathrm{Si}$ as an internal standard, and all samples were prepared in $\mathrm{CDCl}_{3}$.

Compounds 1-7 (Table 1) were synthesized according to the procedure reported previously (Kikuchi et al., 1990). 


\section{5-(3-Ethoxyphenyl)-1-neopentylimidazole (8)}

A mixture of $1.3 \mathrm{~g}$ of m-hydroxybenzaldehyde, $\mathrm{lg}$ of neopentylamine and $6 \mathrm{~g}$ of anhydrous $\mathrm{MgSO}_{4}$ in $30 \mathrm{ml}$ of dichloromethane was refluxed for $2 \mathrm{hr}$. $\mathrm{MgSO}_{4}$ was filtered off, and the filtrate was concentrated under reduced pressure. The residue was dissolved in $20 \mathrm{ml}$ of methanol, and to the mixture was added $6 \mathrm{~g}$ of anhydrous $\mathrm{K}_{2} \mathrm{CO}_{3}$ and $2.5 \mathrm{~g}$ of tosylmethylisocyanide (TosMIC). After refluxing for $2 \mathrm{hr}$, the solvent was evaporated and water $(70 \mathrm{ml})$ was added to the residue. The precipitate was collected by filtration and recrystallized from ethanol and water to afford $0.8 \mathrm{~g}$ (33 $\%$ ) of 5-(3-hydroxyphenyl)-1-neopentylimidazole, mp $215 \sim 217^{\circ} \mathrm{C}$.

To a suspension of $0.1 \mathrm{~g}$ of sodium hydride $(60 \%$ in oil) in $10 \mathrm{ml}$ of dimethylformamide was added $0.46 \mathrm{~g}$ of the above compound, and the mixture was stirred for $1 \mathrm{hr}$ at room temperature. To the mixture was added $0.22 \mathrm{~g}$ of ethyl bromide at $0-5^{\circ} \mathrm{C}$. After stirring for $20 \mathrm{hr}$ at room temperature, to the mixture was added $50 \mathrm{ml}$ of water, and the product was extracted with ether. The ether solution was washed with brine and dried over $\mathrm{Na}_{2} \mathrm{SO}_{4}$. After removal of the solvent, the residue was chromatographed on silica gel by elution with hexane-ethyl acetate $(2: 1)$ and $(1: 1)$. Concentration of the hexane-ethyl acetate $(1: 1)$ eluate under reduced pressure followed by recrystallization of the residue from hexane afforded $0.35 \mathrm{~g}(68 \%)$ of $8, \mathrm{mp} 67-68^{\circ} \mathrm{C}$. NMR $\delta$ : $0.74(9 \mathrm{H}, \mathrm{s}), 1.42(3 \mathrm{H}, \mathrm{t}, \mathrm{J}=7 \mathrm{~Hz}), 3.82(2 \mathrm{H}, \mathrm{s}), 4.02(2 \mathrm{H}, \mathrm{q}, \mathrm{J}=7 \mathrm{~Hz}), 6.7-7.5(6 \mathrm{H}, \mathrm{m})$. Anal. Found : C, $74.49 ; \mathrm{H}, 8.56 ; \mathrm{N}, 10.70$. Calcd. for $\mathrm{C}_{16} \mathrm{H}_{22} \mathrm{~N}_{2} \mathrm{O}: \mathrm{C}, 74.42 ; \mathrm{H}, 8.53 ; \mathrm{N}$, $10.85 \%$.

5 -( 4 -Ethoxyphenyl)-1-neopen tylimidazole (9) was prepared in the same manner as 8 , using p-hydroxybenzaldehyde. Yield $66 \%$ mp 70-72 $\mathrm{C}$. NMR $\delta: 0.74(9 \mathrm{H}, \mathrm{s}), 1$. $44(3 \mathrm{H}, \mathrm{t}, \mathrm{J}=7 \mathrm{~Hz}), 3.76(2 \mathrm{H}, \mathrm{s}), 4.05(2 \mathrm{H}, \mathrm{q}, \mathrm{J}=7 \mathrm{~Hz}), 6.7-7.5(6 \mathrm{H}, \mathrm{m}) . \quad$ Anal. Found : $\mathrm{C}$, $74.39 ; \mathrm{H}, 8.60 ; \mathrm{N}, 10.83$. Calcd. for $\mathrm{C}_{16} \mathrm{H}_{22} \mathrm{~N}_{2} \mathrm{O}: \mathrm{C}, 74.42 ; \mathrm{H}, 8.53 ; \mathrm{N}, 10.85 \%$.

Compounds 11-13 were similarly prepared, starting from compound 5 and the corresponding alkyl bromides.

1-Neopentyl-5-(2-propoxyphenyl) imidazole (11). Yield 81\%. NMR $\delta: 0.72(9 \mathrm{H}$, s), $0.90(3 \mathrm{H}, \mathrm{t}, \mathrm{J}=7 \mathrm{~Hz}), 1.45-1.90(2 \mathrm{H}, \mathrm{m}), 3.66(2 \mathrm{H}, \mathrm{s}), 3.86(2 \mathrm{H}, \mathrm{t}, \mathrm{J}=7 \mathrm{~Hz}), 6.7-7.5(6 \mathrm{H}$, $\mathrm{m})$.

5-(2-Isopropoxyphenyl)-1-neopentylimidazole (12) Yield 28\%. NMR $\delta: 0.72(9 \mathrm{H}$, s), $1.20(6 \mathrm{H}, \mathrm{d}, \mathrm{J}=6 \mathrm{~Hz}), 3.73(2 \mathrm{H}, \mathrm{s}), 4.2-4.6(1 \mathrm{H}, \mathrm{m}), 6.8-7.6(6 \mathrm{H}, \mathrm{m})$.

5-(2-Isobutoxyphenyl)-1-neopentylimidazole (13) Yield $21 \%$. NMR $\delta: 0.72(9 \mathrm{H}$, s), $0.88(6 \mathrm{H}, \mathrm{d}, \mathrm{J}=6 \mathrm{~Hz}), 1.7-2.1(1 \mathrm{H}, \mathrm{m}), 3.64(2 \mathrm{H}, \mathrm{d}, \mathrm{J}=6 \mathrm{~Hz}), 3.66(2 \mathrm{H}, \mathrm{s}), 6.7-7.5(6 \mathrm{H}$, $\mathrm{m})$.

5-(4-Methoxyphenyl)-1-neopentylimidazole (10). A mixture of 1.4g of $p$-methoxybenzaldehyde, $1.2 \mathrm{~g}$ of neopentylamine, and $5 \mathrm{~g}$ of anhydrous $\mathrm{MgSO}_{4}$ in $30 \mathrm{ml}$ of dichloromethane was refluxed for $2 \mathrm{hr} . \mathrm{MgSO}_{4}$ was filtered off and the filtrate was concentrated under reduced pressure. The residue was dissolved in $20 \mathrm{ml}$ of methanol, and to the mixture was added $5 \mathrm{~g}$ of $\mathrm{K}_{2} \mathrm{CO}_{3}$ and $2.5 \mathrm{~g}$ of tosylmethylisocyanide. After refluxing for $2 \mathrm{hr}$, the solvent was evaporated and the product was extracted with ether. The ether solution was washed with brine and dried over $\mathrm{Na}_{2} \mathrm{SO}_{4}$. After removal of the solvent, the residue was chromatographed on silica gel by elution with hexane-ethyl acetate $(3: 1)$ and $(1: 1)$. Concentration of the hexane-ethyl acetate $(1: 1)$ eluate under reduced pressure followed by recrystallization of the residue from hexane afforded $0.2 \mathrm{~g}(41 \%)$ of $10, \mathrm{mp} 1022103^{\circ} \mathrm{C}$. NMR $\delta: 0.73(9 \mathrm{H}, \mathrm{s}), 3.76(2 \mathrm{H}, \mathrm{s}), 3.82(3 \mathrm{H}$, 
s), 6.7-7.5 (6H, m). Anal. Found: $\mathrm{C}, 73.77 ; \mathrm{H}, 8.27 ; N, 11.39$. Calcd. for $\mathrm{C}_{15} \mathrm{H}_{20} \mathrm{~N}_{2} \mathrm{O}$ : C, $73.77 ; \mathrm{H}, 8.20 ; \mathrm{N}, 11.48 \%$.

Compounds 14-23 were similarly prepared, starting from the appropriate substituted benzaldehyde and neopentylamine.

5-(2-methylphenyl)-1-neopentylimidazole (14). Yield 5.7\%. NMR $\delta: 0.76(9 \mathrm{H}$, s), $2.16(3 \mathrm{H}, \mathrm{s}), 3.57(2 \mathrm{H}, \mathrm{s}), 6.90(1 \mathrm{H}, \mathrm{s}), 7.0-7.3(4 \mathrm{H}, \mathrm{m}), 7.52(1 \mathrm{H}$, broad s).

5-(3-methylphenyl)-1-neopentylimidazole (15). Yield $4.4 \% . \mathrm{mp} 72-74^{\circ} \mathrm{C}$. NMR $\delta: 0.73(9 \mathrm{H}, \mathrm{s}), 2.36(3 \mathrm{H}, \mathrm{s}), 3.84(2 \mathrm{H}, \mathrm{s}), 6.9-7.4(5 \mathrm{H}, \mathrm{s}), 7.94(1 \mathrm{H}$, broad s).

5-(4-methylphenyl)-1-neopentylimidazole (16). Yield $4.4 \% . \mathrm{mp} 98-99^{\circ} \mathrm{C}$ (recrystallized from hexane). NMR $\delta: 0.72(9 \mathrm{H}, \mathrm{s}), 2.37(3 \mathrm{H}, \mathrm{s}), 3.80(2 \mathrm{H}, \mathrm{s}), 6.95(1 \mathrm{H}$, broad s), 7.14-7.24 $(4 \mathrm{H}, \mathrm{m}), 7.46(1 \mathrm{H}$, broad s). Anal. Found: C, $78.67 ; \mathrm{H}, 8.74 ; \mathrm{N}, 12.21$. Calcd. for $\mathrm{C}_{15} \mathrm{H}_{20} \mathrm{~N}_{2}: C, 78.95 ; \mathrm{H}, 8.77 ; \mathrm{N}, 12.28 \%$.

5-(4-Ethylphenyl)-1-neopentylimidazole (17). Yield $6.7 \%$ mp $45-47^{\circ} \mathrm{C} . \mathrm{NMR}$ $\delta: 0.72(9 \mathrm{H}, \mathrm{s}), 1.26(3 \mathrm{H}, \mathrm{t}, \mathrm{J}=7 \mathrm{~Hz}), 2.66(2 \mathrm{H}, \mathrm{q}, \mathrm{J}=7 \mathrm{~Hz}), 3.80(2 \mathrm{H}, \mathrm{s}), 6.94(1 \mathrm{H}$, broad s), 7.06-7.12(4H, m), 7.46(1H, broad s).

5-(4-Bromophenyl)-1-neopentylimidazole (18). Yield $1.1 \% . \mathrm{mp} 127-130^{\circ} \mathrm{C}$. NMR $\delta: 0.72(9 \mathrm{H}, \mathrm{s}), 3.78(2 \mathrm{H}, \mathrm{s}), 6.9-7.6(6 \mathrm{H}, \mathrm{m})$.

5-(3,4-Dichlorophenyl)-1-neopentylimidazole (19). Yield $0.7 \%$ mp 132-134 ${ }^{\circ} \mathrm{C}$. NMR $\delta: 0.74(9 \mathrm{H}, \mathrm{s}), 3.78(2 \mathrm{H}, \mathrm{s}), 6.98(1 \mathrm{H}$, broad s), $7.10(1 \mathrm{H}, \mathrm{dd}, \mathrm{Ja}=7 \mathrm{~Hz}, \mathrm{Jb}=2 \mathrm{~Hz}), 7$. $36(1 \mathrm{H}, \mathrm{d}, \mathrm{J}=2 \mathrm{~Hz}), 7.44(1 \mathrm{H}, \mathrm{d}, \mathrm{J}=7 \mathrm{~Hz}), 7.50(1 \mathrm{H}$, broad s).

1-Neopentyl-5-(4-nitrophenyl) imidazole (20). Yield $1.0 \% . \mathrm{mp} 125-128^{\circ} \mathrm{C}$. NMR $6: 0.72(9 \mathrm{H}, \mathrm{s}), 3.84(2 \mathrm{H}, \mathrm{s}), 7.08(1 \mathrm{H}$, broad s), $7.44(2 \mathrm{H}, \mathrm{d}, \mathrm{J}=8 \mathrm{~Hz}), 7.52(1 \mathrm{H}$, broad s), $8.22(2 \mathrm{H}, \mathrm{d}, \mathrm{J}=8 \mathrm{~Hz})$.

5-(3,4-methylenedioxyphenyl)-1-neopentylimidazole (21). Yield $4.3 \%$ mp 123$125^{\circ} \mathrm{C}$. NMR $\delta: 0.74(9 \mathrm{H}, \mathrm{s}), 3.74(2 \mathrm{H}, \mathrm{s}), 5.96(2 \mathrm{H}, \mathrm{s}), 6.64-6.96(4 \mathrm{H}, \mathrm{m}), 7.44(1 \mathrm{H}$, broad s).

5-(1-Naphthyl)-1-neopentylimidazole (22). Yield $2.9 \%$ NMR $\delta: 0.68(9 \mathrm{H}, \mathrm{s}), 7$. $07(1 \mathrm{H}$, broad s), 7.24-7.92 $(8 \mathrm{H}, \mathrm{m})$.

5-(2-Naphthyl)-1-neopentylimidazole (23 ). Yield $2.3 \% \mathrm{mp} 128-130^{\circ} \mathrm{C}$ (recrystallized from hexane). NMR $\delta: 0.72(9 \mathrm{H}, \mathrm{s}), 3.88(2 \mathrm{H}, \mathrm{s}), 7.06(1 \mathrm{H}$, broad s), 7.28-7.90 $(8 \mathrm{H}, \mathrm{m})$. Anal. Found : C, $81.70 ; \mathrm{H}, 7.60 ; \mathrm{N}, 10.54$. Calcd. for $\mathrm{C}_{18} \mathrm{H}_{20} \mathrm{~N}_{2}: \mathrm{C}, 81.82 ; \mathrm{H}$, $7.58 ; \mathrm{N}, 10.61 \%$.

Bioassays

Bombyx mori (Gunpo x Shugyoku, C. $137 \mathrm{x}$ N. 137) larvae were reared on artificial, diets, Silkmate $1 S$ and 2M (Nippon Nosan Kogyo Co., Ltd) for 1st instar and the 2nd to 5th instar larvae, respectively, under a $12 \mathrm{hr}$ light and $12 \mathrm{hr}$ dark photoperiod at $26 \pm 2^{\circ} \mathrm{C}$. The compounds in an acetone solution (1-4 $\mu \mathrm{g} /$ larva) were applied topically to newly molted 4th instar and $24 \mathrm{hr}$-old 3 rd instar larvae of B. mori. The activity was evaluated by the induction of precocious metamorphosis : spinning a coccon and then pupation in the 3rd or 4th instar (penultimate) period. The lethal effect was defined as mortality within the same larval stage after treatment.

\section{RESULTS AND DISCUSSIONS}

Syntheses

1-Neopentyl-5-substituted imidazoles were prepared according to procedures 


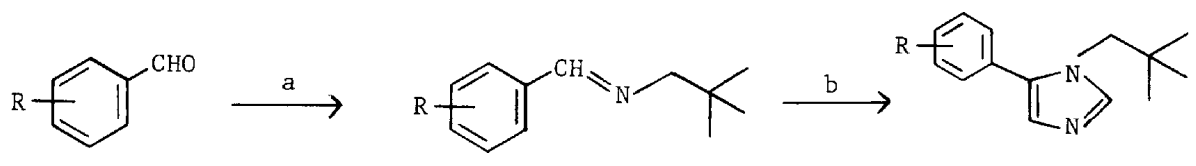

Reagents ; (a) neopentylamine, $\mathrm{MgSO}_{4}, \mathrm{CH}_{2} \mathrm{Cl}_{2}$; (b) TosMIC, $\mathrm{K}_{2} \mathrm{CO}_{3}, \mathrm{MeOH}$,

Scheme 1. Synthesis of 1-neopentyl-5-substituted imidazoles

Table 1. Induction of precocious metamorphosis in the silkworm (Gunpo $\mathrm{x}$ Shugyoku) by 1 neopentyl -5 -substituted imidazoles.<smiles>[2H]c1cncn1CC(C)(C)C</smiles>

$\mathrm{R}$
Precocious metamorphosis (\%)

NO.

Phenyl

2 - Chlorophenyl

3 - Chlorophenyl

4 - Chlorophenyl

2 - Hydroxyphenyl

2 - Methoxyphenyl

2 - Ethoxyphenyl

3 - Ethoxyphenyl

4 -Ethoxyphenyl

4 - Methoxyphenyl

2 - Propoxyphenyl

2 - Isopropoxyphenyl

2 - Isobutoxyphenyl

2- Methylphenyl

3-Methylphenyl

4 - Methylphenyl

4 - Ethylphenyl

4- Bromophenyl

3,4-Dichlorophenyl

4 - Nitrophenyl

3,4- Methylenedioxyphenyl

1 - Naphthyl

2- Naphthyl

$(\mu \mathrm{g} /$ larva) $\quad 20$

10

2

tested

described by van Leusen et al. (1977). The imines derived from neopentylamine and substituted benzaldehydes were treated with tosylmethylisocyanide (TosMIC) in the presence of potassium carbonate as a base in methanol to afford 1-neopentyl-5substituted imidazoles (Scheme 1). In this method compounds 14-23 were prepared in low yield, whereas 5-(hydroxyphenyl)-1-neopentylimidazoles (e. g. compound 5) were obtained in relatively high yield because of presumably the stability of the imines derived from hydroxybenzaldehydes. Compounds 8-13 in Table 1 were prepared by standard alkylation of the corresponding 5-(hydroxyphenyl)-1-neopentylimidazoles.

Biological activities

The bioassay data for 1-neopentyl-5-substituted imidazoles on the 4th instar 
larvae of B.mori are given in Table 1. As described in a previous paper (Kuwano et al., 1988), in a series of 1-substituted-5-pheylimidazoles the 1-neopentyl analog 1 showed the highest activity. So modifications were made in the 5-position of the imidazole ring by introducing various substituents on the benzene ring. The introduction of a 4-chloro substituent on the benzene ring (4) increased activity in comparison with that observed for the parent compound 1, whereas the 2-chlorophenyl analog 2 showed much less activity and the 3-chlorophenyl analog 3 was as active as 1 . Interestingly, the 3,4-dichlorophenyl analog 19 was quite inactive at $20 \mu \mathrm{g}$. The $2-$ hydroxyphenyl analog 5 had no activity at $20 \mu \mathrm{g}$, presumably due to the polarity of the hydroxy group.

The 2-methoxy-(6) and 2-ethoxyphenyl (7) analogs were more effective than unsubstituted 1. The location of an alkoxy group was important for activity. The 3and 4-alkoxy analogs (S-10) decreased the activity compared with that of 1 . The activity in the 22alkoxyphenyl analogs was found to fall off with increasing size of the alkyl chain (11-13). The 2-methylphenyl analog 14 exhibited high activity as well as compounds 6 and 7. However, the introduction of an alkyl group at the meta or para position on the benzene ring decreased activity (15-17).

In contrast to 4-alkoxy-and 4-alkylphenyl analogs, the 4-bromophenyl analog 18 showed relatively high activity. The 4-nitrophenyl (20) and 3, 4-methylenedioxyphenyl (21) analogs showed low activity. The 1-naphthyl analog 22 had almost the same activity as that of compound 1, whereas the 2-naphthyl analog 23 did not induce precocious metamorphosis even at a dose of $20 \mu \mathrm{g}$.

In Table 2 there are presented the $\mathrm{ED}$, , values for several representative 1,5 disubstituted imidazoles showing high activity. The 2-methoxylphenyl analog 6 was the most active of the series of 1-neopentyl-5-substituted imidazoles and compounds 4, 7, 14 and 18 showed higher activity than KK-22 which has been reported to be highly active to the silkworm for the first time. However, these compounds were somewhat less active in comparison with $\mathrm{KK}-42$, which has been the most effective of the imidazole compounds so far tested on the silkworm.

The induction of precocious metamorphosis with compounds 4,7 and 14 was inhibited by simultaneous application of methoprene, a $\mathrm{JH}$ mimic, as shown in Table 3. Those three compounds $(10 \mu \mathrm{g} /$ larva) induced precocious metamorphosis in $100 \%$

Table 2. Induction of precocious metamorphosis in the silkworm (C. $137 \times$ N. 137) by 1,5 -disubstituted imidazoles.

\begin{tabular}{lc}
\hline Compound & ED,,$(\mu \mathrm{g} /$ larva $)$ \\
\hline $4(\mathrm{KK}-135)$ & 2.1 \\
6 & 1.1 \\
$7(\mathrm{KK}-110)$ & 1.6 \\
11 & 2.9 \\
14 & 1.5 \\
18 & 2.2 \\
22 & 2.8 \\
$\mathrm{KK}-22$ & 2.8 \\
$\mathrm{~K} \mathrm{~K}-42$ & 0.4 \\
\hline
\end{tabular}


Table 3. Counteraction by methoprene on the effects of $1-$ neopentyl $-5-$ substituted imidazoles for the 4 th instar larvae.

\begin{tabular}{ccc} 
& Precocious metamorphosis & $(\%)$ \\
\cline { 2 - 3 } $\begin{array}{l}\text { Compound } \\
(10 \mu \mathrm{g} / \text { larva })\end{array}$ & 0 & 10 \\
\cline { 2 - 3 } & 100 & 0 \\
$7(\mathrm{KK}-135)$ & 100 & 0 \\
$7(\mathrm{KK}-110)$ & 100 & 0 \\
\hline
\end{tabular}

Table 4. Effects of compounds $4(\mathrm{KK}-135)$ and $7(\mathrm{KK}-110)$ on the 3rd instar larvae of B.mori

\begin{tabular}{|c|c|c|c|c|c|c|}
\hline \multirow[b]{2}{*}{ Compound } & \multirow[b]{2}{*}{$\begin{array}{l}\text { dose } \\
(\mu \mathrm{g})\end{array}$} & \multirow[b]{2}{*}{$\begin{array}{c}\text { No. of } \\
\text { dead larvae }\end{array}$} & \multicolumn{4}{|c|}{ No. of larvae which spun cocoons at } \\
\hline & & & $3 \mathrm{rd}$ & 4 th & 5 th & (instar) \\
\hline \multirow{8}{*}{$4 \quad(\mathrm{KK}-135)$} & 1 & 0 & 0 & 1 & 19 & \\
\hline & 2 & 0 & 0 & 16 & 4 & \\
\hline & 5 & 0 & 0 & 20 & 0 & \\
\hline & 10 & 0 & 0 & 20 & 0 & \\
\hline & 20 & & 0 & 19 & 0 & \\
\hline & 40 & 0 & 1 & 19 & 0 & \\
\hline & 60 & 0 & 1 & 19 & 0 & \\
\hline & 80 & 1 & 6 & 13 & 0 & \\
\hline \multirow{8}{*}{$7(\mathrm{KK}-110)$} & 1 & 0 & 0 & 4 & 16 & \\
\hline & 2 & 0 & 0 & 18 & 2 & \\
\hline & 5 & 0 & 0 & 20 & 0 & \\
\hline & 10 & 0 & 0 & 20 & 0 & \\
\hline & 20 & 3 & 0 & 17 & 0 & \\
\hline & 40 & 2 & 0 & 18 & 0 & \\
\hline & 60 & 6 & 4 & 10 & 0 & \\
\hline & 80 & 14 & 1 & 5 & 0 & \\
\hline Control & & 0 & 0 & 0 & 20 & \\
\hline
\end{tabular}

No. of larvae tested $=20$

of the 4th instarlarvae, while all of the larvae molted into normal 5th instar when 10 $\mu \mathrm{g}$ of methoprene was topically applied to those treated with compounds. This result indicated that 1-neopentyl-5-substituted imidazoles induced precocious metamorphosis by causing a JH-deficiency in the hemolymph of the silkworm larvae.

Table 4 shows the effects of two representative compounds $4(\mathrm{KK}-135)$ and 7 (KK -110) on the 3rd instar larvae ( $24 \mathrm{hr}$ old larvae after the 2 nd ecdysis). When the 3rd instar larvae were treated with low doses $(1-20 \mu \mathrm{g})$ of both compounds, precocious pupation occurred in the 4th (penultimate) larval stage. At high doses of 60 and $80 \mu \mathrm{g}$ some of larvae spun at the end of the 3rd instar larval stage and then metamorphosed into precocious miniature pupae, even though the percentage was low. In this case a few pupae molted to the miniature adults, but most of the pupae failed in adult 
emergence.

KK-110 exhibited more toxicity than KK-135. The lethal effect occurred within the 3rd larval stage after treatment. It seems that this acute toxicity was not related to the $\mathrm{JH}$-deficiency symptom, because concurrent application of methoprene did not rescue this mortality.

It has been reported that KK-42 inhibited ecdysteroid synthesis in the prothoracic glands of B. mori (Yamashita et al., 1987) and Locustamigratoria (Roussel et al., 1987) in vitro at a low dose. Recently Akai et al. (1989) have found that KK-42 depressed the $\mathrm{JH}$ amount in the hemolymph of B. mori larvae. Although the precise mode of action of KK-42 is still unknown, a new series of 1,5-disubstituted imidazoles might hold promise as insect growth regulators.

\section{REFERENCES}

Kikuchi, M., E. Kuwano and M. Eto 1990 Synthesis and plant growth regulatory activity of 1, 5disubstituted imidazoles. J. Fac. Agr., Kyusku Univ., 34 : 397-404

Kuwano, E., R. Takeya and M. Eto 1984 Synthesis and anti-juvenile hormone activity of 1-citronellyl-5-substituted imidazoles. Agric. Biol.Ckem., $48: 3115-3119$

Kuwano, E., R. Takeya and M. Eto 1985 Synthesis and anti-juvenile hormone activity of 1-substituted-5-[(E)-2,6-dimethyl-1,5-heptadienyl $]$ imidazoles. Agric. Bid. Ckem., 49 : 483-486

Kuwano, E., M. Kikuchi and M. Eto 1988 Induction of precocious metamorphosis by 1, 5-disubstituted imidazoles with a non-terpene chain. Agric. Biol.Ckem., $52: 1619-1620$

Roussel, J-P., M. Kiuchi, H. Akai and E. Kuwano 1987 Effets d'un derive de l'imidazole (KK-42) sur la biosynthese de l'ecdysone par les glandes prothoraciques de Locusta migratoria(Insecte, Orthoptere), in vitro. C. R. Acad.Sci. Paris, $305: 141-144$

Van Leusen, A. M., J. Wildeman and 0. H. Oldenziel 1977 Base-induced cycloaddition of sulfonylmethyl isocyanides to C, N, double bonds. Synthesis of 1, 5-disubstituted and 1, 4, 5trisubstituted imidazoles from aldimines and imidoyl chlorides. J.Org. Ckem., $42: 1153-1159$

Yamashita, O., K. Kadono-Okuda, E. Kuwano and M. Eto 1987 An imidazole compound as a potent anti-ecdysteroid in an insect. Agric. Biol. Ckem., 51: 2295-2297 